twice the winter value. The discrepancy has been traced to the effect of solar heating which causes the air to expand. The expansion, in turn, dilutes the electrical concentration proportionally with the reduction of air density.

It may, at first sight, seem impossible for human beings to be able to affect conditions at high levels, and yet it has recently been found that powerful wireless stations can increase to a very small extent the temperature of the Kennelly-Heaviside layer. Due to the modulation of such a station, the slight heating varies rhythmically with the speech or music being transmitted and the programme is, as it were, stored up in the absorptive properties of the layer. The effect of this is most unfortunate, for any other waves reflected at the affected patch acquire the modulation of the unwanted programme. The result is that listeners may find an undesired programme obtruding when they are listening to a station on quite a different wave-length. The practical consequence of this so-called 'Luxembourg effect' appears to be that until it is possible to reduce the upward radiation towards the Kennelly-Heaviside layer, there is a certain amount of danger in increasing the power of long-wave broadcasting stations beyond a certain limit.

\title{
Effect of Fog upon Plant Growth
}

$\mathrm{O}$ ING to the severe damage caused by London fogs to orchid flowers, begonias and other plants at the Royal Botanic Gardens, Kew, experiments have been carried out at Kew during the past few months with (1) ammonia, (2) electric fans. These experiments were described by Sir Arthur Hill at the Linnean Society on January 30. A 2 per cent solution of ammonia was placed in trays on the floor of the house where begonias, "Gloire de Lorraine", etc., were in flower, with the object of neutralising the sulphuric acid present in the fogs. Very little shedding of flowers or leaves took place beyond what is normal at this season. Electric fans were installed in the Tropical Begonia and Tropical Orchid Houses, and proved quite successful during the bad fogs in December 1935. Calanthe flowers remained uninjured, whereas in an adjoining similar house without fans all the flower spikes were seriously damaged and blackened.

During the bad fogs in mid-January, however, when snow fell at the same time, the fans were not so effective, and it seems probable that the humidity of the houses was unduly high at the time and the fans ceased to lower the humidity, so that the injurious matters in the fog were able to be effective. It seems clear from the experiments carried out so far that the fog damage is elosely linked with temperature and moisture conditions, and immunity can only be effected by careful adjustment of these two factors.

Specimens of Calanthe influorescence were shown at the meeting, some entirely blackened and wholly spoilt, some with the older buds injured, others fairly normal.

Dr. C. R. Metcalfe made microscopical examinations of the leaves which fell in the houses unprovided with fans or ammonia. $\mathrm{He}$ finds that when leaves of begonias and other plants fall off during foggy weather, the petioles sometimes break where an absciss layer is present, but in other instances an irregular fracture occurs. No evidence has been found that foggy weather stimulates the formation of absciss layers. Granular material, which stains readily with alkannin, tends to accumulate at the points where the leaves break off.

\section{Bicyclic Terpenes}

$\mathrm{I}^{\mathrm{N}}$ his presidential address to the Chemistry Section of the twenty-third Indian Science Congress held at Indore on January 2-8, Dr. P. C. Guha reviewed at length recent developments in the chemistry of the bicyclic terpenes, derivatives of camphane, santane, pinane, thujane and carane being reviewed in turn.

Apart from the very obvious importance of a detailed study of natural products, one of the most interesting developments in recent years has been to widen the scope of stereochemical problems. Thus the study of decalin (decahydronaphthalene), the parent hydrocarbon of the sesquiterpenes, led Hückel to the discovery of a new type of stereoisomerism arising out of the cis and trans interlockings of two monocyclic structures to multiplanar molecules. This work and that of Ruzicka on the stability of poly. membered carbon rings have provided strong arguments against Baeyer's uniplanar models for cyclohexane and higher carbon rings; but in discussing the work of Linstead and Barrett on the bicyelo- octanes, the author has overlooked the fact that the multiplanar configurations assigned by Hückel to the decalins and hydrindanes have been conclusively confirmed recently by the discovery of the existence of optical isomerism in certain of their derivatives.

The interesting reaction described by Diels and Adler in 1928, in which a conjugated system of double bonds is caused to combine additively in the 1.4 positions with compounds containing the grouping $-\mathrm{CH}=\mathrm{CH}-\mathrm{CO}-$, has opened the way to the synthesis of many bicyclic terpene derivatives, including camphor compounds, and the systematic study of the degradation products in the fenchane and camphane series has progressed steadily. A new type of intramolecular rearrangement has been described by Nametkin in which $\alpha$-methylcamphene on hydration yields 4-methylisoborneol instead of the 6-methylisomer which would be expected from the usual Wagner mechanism. The published address (Calcutta: Asiatic Society of Bengal) includes a useful classified bibliography. 